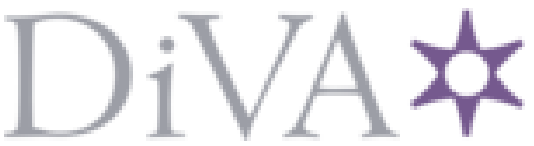

http://www.diva-portal.org

Preprint

This is the submitted version of a paper published in International Journal of Pharmaceutics.

Citation for the original published paper (version of record):

Boge, L., Umerska, A., Matougui, N., Bysell, H., Ringstad, L. et al. (2017)

Cubosomes post-loaded with antimicrobial peptides: Characterization, bactericidal effect and proteolytic stability

International Journal of Pharmaceutics, 526(1-2): 400-412

https://doi.org/10.1016/j.ijpharm.2017.04.082

Access to the published version may require subscription.

N.B. When citing this work, cite the original published paper.

Permanent link to this version:

http://urn.kb.se/resolve?urn=urn:nbn:se:ri:diva-30o31 


\title{
Cubosomes post-loaded with antimicrobial peptides: characterization, bactericidal effect and proteolytic stability
}

\author{
Lukas Boge $^{* 1,6}$, Anita Umerska ${ }^{2-3}$, Nada Matougui ${ }^{2-3}$, Helena Bysell ${ }^{1}$, Lovisa Ringstad ${ }^{1}$, Mina Davoudi ${ }^{4}$, Jonny \\ Eriksson $^{5}$, Katarina Edwards ${ }^{5}$, Martin Andersson ${ }^{6}$ \\ ${ }^{1}$ SP Technical Research Institute of Sweden, Drottning Kristinas väg 45 Box 5607 Stockholm SE 11486, +46105166078 \\ lukas.boge@sp.se, ${ }^{2}$ INSERM U 1066, 'Micro et Nanomédecines biomimétiques - MINT', Angers, France, ${ }^{3}$ Université Angers, \\ UMR-S1066 Angers, France, ${ }^{4}$ Division of Dermatology and Venereology, Department of Clinical Sciences, Lund University, \\ SE-221 84 Lund, Sweden, ${ }^{5}$ Department of Chemistry - BMC, Uppsala University, Husargatan 3 Box 579 Uppsala SE-75123, 6 \\ Department of Chemistry and Chemical Engineering, Applied Chemistry, Chalmers University of Technology, Kemigården 4 \\ Göteborg SE-41296
}

Corresponding author: Lukas Boge, lukas.boge@sp.se, +46706986078

\section{Graphical abstract:}

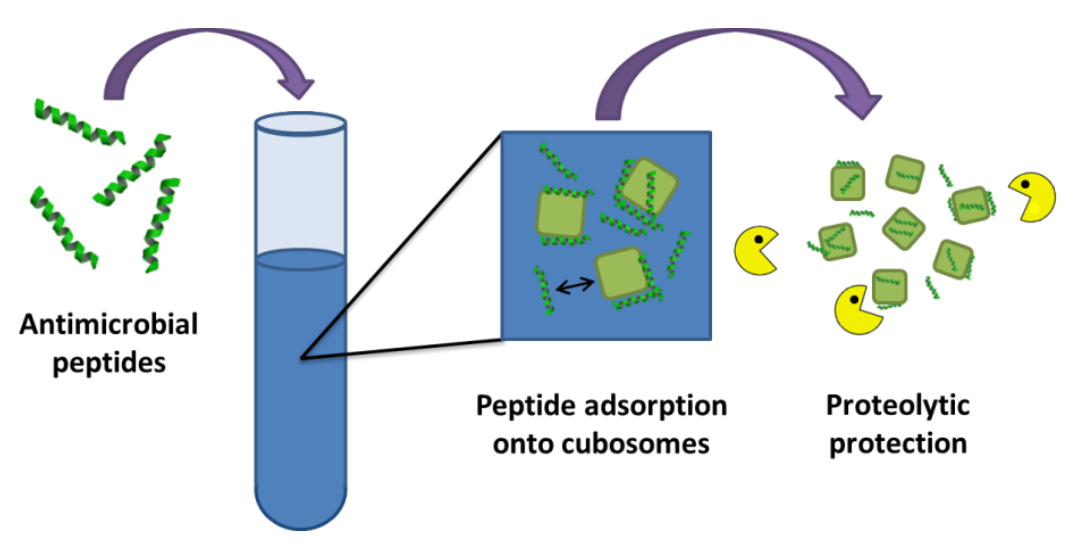

\begin{abstract}
Novel antibiotics, such as antimicrobial peptides (AMPs), have recently attended more and more attraction. In this work, dispersed cubic liquid crystalline gel (cubosomes) was used as drug delivery vehicles for three AMPs (AP114, DPK-060 and LL-37). Association of peptides onto cubosomes was studied at two cubosome/peptide ratios using high performance liquid chromatography, $\zeta$-potential and circular dichroism measurements. AMPs impact on the cubosome structure was investigated using small angle $x$-ray scattering and cryogenic transmission electron microscopy. The antimicrobial effect of the AMP loaded cubosomes was studied in vitro by minimum inhibitory concentration and time-kill assays. Proteolytic protection was investigated by incubating the formulations with two elastases and the antimicrobial effect after proteolysis were studied using radial diffusion assay. Different association efficacy onto the cubosomes was observed among the AMPs, with LL-37 showing greatest association ( $>60 \%$ ). AP114 loaded cubosomes displayed a preserved antimicrobial effect, whereas for LL-37 the broad spectrum bacterial killing was reduced to only comprise Gramnegative bacteria. Interestingly, DPK-060 loaded cubosomes showed a slight enhanced effect against S. aureus and E. coli strains. Moreover, the cubosomes were found to protect LL-37 from proteolytic degradation, resulting in a significantly better bactericidal effect after being subjected to elastase, compared to unformulated peptide.
\end{abstract}

Keywords: cubosome, liquid crystalline nanoparticle, glycerol monooleate, antimicrobial peptide, AMP, proteolysis 


\section{Introduction}

The demand for novel antibiotic treatments is alarming within the health sector and is doubtless a necessity in order to treat the increasing number of infections caused by antimicrobial resistant bacteria. A group of novel antimicrobial agents that has gained a lot of attraction since the early 1980's are antimicrobial peptides (AMPs) (Pasupuleti et al., 2012). Key features of AMPs are their amphiphilicity and positive net charge, driving the adsorption onto the slightly negatively charged bacterial membranes (Hancock and Lehrer, 1998). Such peptides generally display a very quick bacterial killing in addition to having a low probability to cause high level resistance (Hancock and Sahl, 2006; Pasupuleti et al., 2012). However, it has been shown that bacteria may develop resistance also to AMPs, and this issue needs to be carefully considered before translation into clinics (Andersson et al., 2016).

AMP's common susceptibility to chemical and proteolytic degradation has limit their use in the clinic. However, formulating the AMPs into smart drug delivery systems may improve these problematic properties (Eckert, 2011; Mahlapuu et al., 2016; Nordström and Malmsten, 2017). Recently, the use of lipid-based nanoparticles as delivery vehicles for protein and peptide drugs has received considerable attention, due to their high degree of biocompatibility and versatility (Matougui et al., 2016). Lyotropic liquid crystalline (LC) structures of polar lipids, such as glycerol monooleate, have the capability of carrying both hydrophilic, lipophilic as well as amphiphilic drugs, making them interesting for use in many different treatments. LC phases based on glycerol monooleate further have the feature that they can be fragmented into liquid crystalline nanoparticles (LCNPs), thus avoiding the very sticky and viscous properties of bulk LC gels (Gustafsson et al., 1996, 1997; Larsson, 1989). LCNPs are commonly prepared by sonication (Gustafsson et al., 1996) or high pressure homogenization of bulk gel using a microfluidizer (Gustafsson et al., 1997) or by dilution of an isotropic mixture of lipid and ethanol, commonly referred to as the hydrotrope method (Spicer et al., 2001). These preparation protocols have the drawback that they also produce a large fraction of vesicles among with the desired LCNPs (usually cubosomes or hexosomes) as can be revealed by cryo-TEM imaging. An approach to reduce the number of vesicles is to hydrothermally treat the sonicated or microfluidized dispersions in an autoclave (Barauskas et al., 2005). This treatment has several advantages, namely: 1) drastically reducing the vesicle content, 2) narrowing down the overall particle size distribution and 3) the final particle dispersion is sterile making it suitable for pharmaceutical use.

Drug loaded LCNPs are typically obtained by adding the drugs either to the molten lipid phase (lipophilic drugs) or to the water phase (hydrophilic drugs) prior to dispersion into nanoparticles. However, peptide and protein drugs are often sensitive to high temperature, which may be induced by the high shearing rates during preparation or by autoclavation during sterilization of the formulations. Hence, the number of preparation techniques for producing drug loaded LCNPs with high degree of uniformity is limited. The formulation strategy used in the present study is to allow water-soluble AMPs to adsorb/associate onto the surface of pre-formed autoclaved LCNPs by means of electrostatic and/or hydrophobic interactions. LCNPs are usually slightly negatively charged and would apparently attract antimicrobial peptides carrying a positive net charge. In this work, three AMPs (AP114, DPK-060 and LL-37) were studied in terms of association behavior (and release from) glycerol monooleate-based LCNPs, with well-defined particle size and structure. Properties of the peptides are summarized in Table 1. AP114 is a gram-positive effective plectasin derivative, acting by inhibiting the membrane biosynthesis (Fischer et al., 2005; Schneider et al., 2010). Plectasins does 
normally contain both $\beta$-sheet and $\alpha$-helical secondary structure elements. The broad-spectrum antimicrobial peptide DPK-060 is an improvement of the human protein kininogen and has shown promising pharmaceutical effect in different skin infections (Eckert, 2011; Schmidtchen et al., 2009). LL-37 is part of the cathelicidin AMP group, found in humans, also displaying a broad spectrum bacterial killing (Dürr et al., 2006). The sensitivity to proteolytic degradation by enzymes has been problematic for translation of LL-37 into clinics (Strömstedt et al., 2009).

Table 1. Properties of the antimicrobial peptides used in the study.

\begin{tabular}{lccccc}
\hline Peptide & MW & $\begin{array}{c}\text { \% hydrophobic } \\
\text { AA }\end{array}$ & $\begin{array}{c}\text { Net charge } \\
\text { (pH 5.5) }\end{array}$ & Secondary structure & $\begin{array}{c}\text { Antibacterial } \\
\text { activity }\end{array}$ \\
\hline AP114 & 4411 & 40 & +4.6 & $\beta$-sheet, $\alpha$-helix & Gram-positive \\
DPK-060 & 2503 & 20 & +8.5 & Linear, random coil & Broad spectrum \\
LL-37 & 4491 & 35 & +6.3 & Linear $\alpha$-helix, random coil & Broad spectrum \\
\hline
\end{tabular}

One example where peptides have been adsorbed onto pre-formed LCNPs is for the labile protein hormone somatostatin (Cervin et al., 2009). An association efficacy of $10-20 \%$ was achieved, but more remarkable was the finding that the in vivo half-life time of the drug was prolonged from 10 minutes to 1 hour (intravenously, rat). Moreover, the effect of adsorbing AMPs (melittin and alameticin) onto liposomes and bilayer-disk particles has been investigated, showing that AMPs have a strong affinity to lipid bilayer structures having a positive curvature (Lundquist et al., 2008; Wessman et al., 2010). Another study showed that melittin was protected from enzymatic degradation by trypsin when the AMP was associated to the surface of lipid-disk particles (Zetterberg et al., 2011).

The aim of this research was to investigate if LCNPs, post-loaded with AMP, could be an alternative to the more conventional formation routes where drugs are loaded prior to dispersion into LCNPs. Moreover, we would like to address if the post-loaded cubosomes could preserve, or enhance, the antimicrobial effect of the AMPs. The bactericidal effect after exposure to clinically relevant proteolytic enzymes, e.g. present in burn wound infections (Pseudomonas aeruginosa elastase and human neutrophil elastase), was also investigated in order to reveal if the cubosomes could protect the peptides against proteolytic attacks. Characterization of the association of AMPs onto the LCNPs was performed by high performance liquid chromatography (HPLC), $\zeta$-potential and circular dichroism (CD) measurements. Release of AMP was monitored using dialysis. The influence of the AMPs on the LC structure and cubosome morphology was examined using synchrotron small angle $x$ ray scattering (SAXS) and cryo-TEM imaging. The in vitro antimicrobial effect of the AMP-loaded particles was studied by minimum inhibitory concentration (MIC) tests and time-kill assays, and the bactericidal effect after incubation with enzyme was assessed using radial diffusion assay (RDA). Moreover, the impact of AMP on bacterial cell's morphology was visualized using scanning electron microscopy (SEM). 


\section{Materials and Methods}

\subsection{Materials}

Glycerol monooleate RYLO MG 19 Pharma was received from Danisco A/S (Grindsted, Denmark). The composition of the sample was specified by the manufacturer as min. $95 \%$ monoglyceride and had a fatty acid content of min. 88\% C18:1. The particle stabilizer, Kolliphor ${ }^{\circledR}$ P407 poly(ethylene oxide)(PEO)-poly(propylene oxide)(PPO)-poly(ethylene oxide)(PEO), was obtained from BASF (Lundwigshafen, Germany) having an average molecular weight of $12600 \mathrm{~g} / \mathrm{mol}$ and an approximate formula of $\mathrm{PEO}_{101} \mathrm{PPO}_{56} \mathrm{PEO}_{101}$. AP114 (GFGCNGPWNEDDLRCHNHCKSIKGYKGGYCAKGGFVCKCY), peptide content $86.2 \%$ (purity $99.1 \%$ ), was provided by Adenium Biotech ApS (Copenhagen, Denmark), DPK-060 (GKHKNKGKKNGKHNGWKWWW), peptide content 72.7\% (purity 98.5\%), was synthesized by Bachem AG (Bubendorf, Swizerland) and provided by Pergamum AB (Stockholm, Sweden) and LL-37 (LLGDFFRKSKEKIGKEFKRIVQRIKDFLRNLVPRTES), peptide content $81.8 \%$ (purity 94.7\%), was synthesized and provided by PolyPeptide Laboratories (Limhamn, Sweden). All AMPs were delivered as lyophilized powders and all substances were used as received without further purification.

\subsection{Sample preparation}

Cubosomes were prepared by the bottom-up approach (Gustafsson et al., 1996, 1997). First, liquid crystalline gels were prepared by mixing melted $\mathrm{GMO}\left(40^{\circ} \mathrm{C}\right)$ with MilliQ water. The composition of GMO:water was 70:30 w/w. Samples were mixed with a spatula, centrifuged ( $2000 \mathrm{rpm}$ for $30 \mathrm{~min}$ ) and allowed to equilibrate at room temperature for at least 48 hours. Then, $0.5 \mathrm{~g}$ gel was fragmented in $9.5 \mathrm{~g}$ of a $1.0 \%$ solution of the stabilizer Kolliphor P407, dissolved in MilliQ water, using an Ultra-Turrax high shear mixer (IKA T25, Staufen, Germany) at $15.000 \mathrm{rpm}$ for 1-2 min. Dispersions were thereafter sonicated using a Vibra-Cell VC 750 (Sonics and Materials Inc., Newton, USA) with a 6 $\mathrm{mm}$ probe operating at $40 \%$ of its maximum power in pulse mode ( $3 \mathrm{~s}$ pulses followed by $7 \mathrm{~s}$ break) for a total time of $5 \mathrm{~min}$. A heat-treatment cycle of the sample was thereafter performed in order to minimize the number of vesicles (Barauskas et al., 2005) in a Laboklav 25 autoclave (SHP Steriltechnik AG, Schloss Detzel/Satuelle, Germany) at $121^{\circ} \mathrm{C}$ for $20 \mathrm{~min}$. The total autoclave cycle was ca. $75 \mathrm{~min}$, including time required to heat-up and cooling down back to room temperature. The final cubosome concentration was defined as the total dry content after the heat-treatment, in $\mathrm{mg} / \mathrm{mL}$ of GMO + P407, and quantified after removal of water through lyophilization (Epsilon 2-4 LSC plus, Martin Christ GmbH, Osterode am Harz, Germany) of the sample. Thereafter, samples containing 5 and 10 $\mathrm{mg} / \mathrm{mL}$ cubosomes, with an AMP content of $100 \mu \mathrm{g} / \mathrm{mL}$ were prepared in $5 \mathrm{mM}$ sodium acetate buffer pH 5.5, as displayed in Table 2. Two different concentrations of particles were chosen in order to investigate how it affected the peptide association. Samples were let to equilibrate for 24 hours at $22 \pm 1^{\circ} \mathrm{C}$ prior to further analyses. 
Table 2. Summary of the prepared samples. AMP concentration was kept fixed at $100 \mu \mathrm{g} / \mathrm{mL}$ while the amount of particles was either 5 or $10 \mathrm{mg} / \mathrm{mL}$. Samples were prepared in $5 \mathrm{mM}$ sodium acetate buffer with or without $150 \mathrm{mM}$ $\mathrm{NaCl}$ at pH 5.5.

\begin{tabular}{cccc}
\hline AMP & $\begin{array}{c}\text { Cubosomes } \\
(\mathrm{mg} / \mathrm{ml})\end{array}$ & $\begin{array}{c}\text { AMP } \\
(\mu \mathrm{g} / \mathrm{mL})\end{array}$ & $\begin{array}{c}\text { Particle/AMP- } \\
\text { ratio }\end{array}$ \\
\hline- & 5 & - & - \\
- & 10 & - & - \\
AP114 & 5 & 100 & 50 \\
AP114 & 10 & 100 & 100 \\
DPK-060 & 5 & 100 & 50 \\
DPK-060 & 10 & 100 & 100 \\
LL-37 & 5 & 100 & 50 \\
LL-37 & 10 & 100 & 100 \\
\hline
\end{tabular}

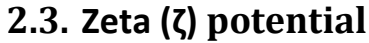

The adsorption of AMP onto cubosomes was monitored by the change in $\zeta$-potential of the particles upon increased peptide concentration, by measuring the electrophoretic mobility with a Zetasizer Zen3600 (Malvern Instruments Ltd., Worcestershire, U.K.). Samples were prepared in $5 \mathrm{mM}$ sodium

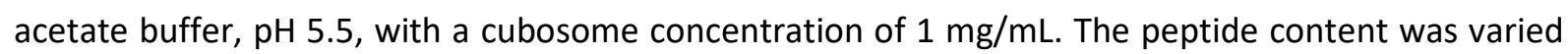
from 20 to $400 \mu \mathrm{g} / \mathrm{mL}$ and the samples were let to equilibrate for 24 hours at $22 \pm 1^{\circ} \mathrm{C}$ prior to analyses. Each sample was analyzed in triplicate using disposable measuring cells at $25^{\circ} \mathrm{C}$. Data is

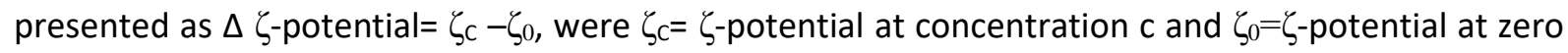
concentration peptide, in order to make the comparison easier between different particle batches.

\subsection{Dynamic light scattering}

The particle size and its distribution were measured by dynamic light scattering (DLS) with a Zetasizer Zen3600 instrument (Malvern Instruments Ltd., Worcestershire, U.K.) after dilution to $2.5 \mathrm{mg} / \mathrm{mL}$ cubosomes. Refractive indices were set to 1.47 and 1.33, for lipids and water respectively. The hydrodynamic radius, assuming spherical particles, was calculated by the software using StokeEinstein's relation to describe the Brownian motion of the particles. Each sample was measured in triplicate using disposable plastic cuvettes at $25^{\circ} \mathrm{C}$.

\subsection{High performance liquid chromatography}

AMP association on the LCNPs was quantified indirectly by separating the LCNPs from the surrounding liquid by centrifugation at $10 \mathrm{000 \textrm {g }}$ for $30 \mathrm{~min}$ through Amicon Ultra-0.5 filter devices (Ultracel-100K, Merck Millipore Ltd. Corc, Ireland) with a $100 \mathrm{kDa}$ molecular weight cut-off. The peptide concentration in the filtrate was then quantified using a high performance liquid chromatography (HPLC) system (Waters Corp., Milford Massachusetts, USA) consisting of AF D92 inline degasser, auto sampler (Model 717 plus), pump and controller (Model 600HPLC) together with a UV absorbance detector (Model 2487 Dual I). The system was equipped with a C18 $5 \mu \mathrm{m}, 4.6 * 250$ $\mathrm{mm}$ ) column (Waters Corp., Milford Massachusetts, USA) operated at room temperature. A flow rate of $1.2 \mathrm{ml} / \mathrm{min}$ was employed using mobile phase $A$ composed of $0.1 \%$ trifluoroacetic acid (TFA) in water and mobile phase $B$ composed of $0.085 \%$ TFA in acetonitrile/water (4:1). A linear gradient was run as following: $10 \%$ B for $5 \mathrm{~min}, 35 \% \mathrm{~B}$ for $9 \mathrm{~min}, 60 \% \mathrm{~B}$ for $0.1 \mathrm{~min}, 100 \% \mathrm{~B}$ for $2 \mathrm{~min}$, and 10\% B for $10.1 \mathrm{~min}$. The injection volume was $20 \mu \mathrm{l}$ and the absorbance was measured at $200 \mathrm{~nm}$ for all peptides. Peptide concentration in the filtrate was determined using a calibration curve and a correction curve compensating for adsorption of peptide to the filter device, measured at several concentrations. The peptide association efficacy to the LCNPs could thereafter be determined as $\%$ of total added peptide. 


\subsection{Release of antimicrobial peptide}

Release of AMP was monitored trough dialysis. $1 \mathrm{~mL}$ of the sample was placed in a Float-A-Lyzer ${ }^{\circledR} \mathrm{G} 2$ dialysis device with 100 kDa MWCO (Spectrum Laboratories Inc., Rancho Dominques, USA) prepared according to manufacturer's instruction. Samples were allowed to dialyze in $12 \mathrm{~mL} 5 \mathrm{mM}$ sodium acetate buffer, $\mathrm{pH} 5.5$, with or without $150 \mathrm{mM}$ sodium chloride, at $22 \pm 1^{\circ} \mathrm{C} .200 \mu \mathrm{L}$ of the sample was withdrawn after $0,1,2,4,6$ and 24 hour of dialysis. The AMP release was quantified by a fluorescamine assay (Böhlen et al., 1973). $180 \mu \mathrm{L}$ of the samples were placed in a black 96-well plate and $20 \mu \mathrm{L} 5 \mathrm{mg} / \mathrm{mL}$ fluorescamine ( $\geq 98 \%$, Sigma Life Science, Saint Louis, USA) dissolved in acetone (99.9\%, Sigma-Aldrich) was added to each well just prior to the fluorescent intensity measurement (excitation $360 \mathrm{~nm}$ and emission $465 \mathrm{~nm}$ ) using a CLARIOstar ${ }^{\circledR}$ plate reader (GMB biotech, Ortenberg, Germany). Peptide quantification was performed using a standard curve with good linearity in the range $1-10 \mu \mathrm{g} / \mathrm{mL}$ peptide $\left(R^{2}=0.996\right.$ for $A P 114, R^{2}=0.991$ for $D P K-060$ and $R^{2}=0.996$ for $\left.L L-37\right)$.

\subsection{Circular dichroism}

Circular dichroism (CD) spectra were obtained using a Jasco J-810 Spectropolarimeter (Jasco, Easton, USA). The measurements were performed at $37^{\circ} \mathrm{C}$ in a $10 \mathrm{~mm}$ quartz cuvette. The samples (100 $\mu \mathrm{g} / \mathrm{mL}$ AMP, $10 \mathrm{mg} / \mathrm{mL}$ cubosomes) were diluted 5 times with buffer ( $5 \mathrm{mM}$ sodium acetate $\mathrm{pH} 5.5$ ) prior to analysis in order to get a good signal from the instrument. The secondary structure of the peptides was monitored in the range $200-260 \mathrm{~nm}$.

\subsection{Small angle $x$-ray scattering}

For structural determination of the AMP-loaded cubosomes, small angle x-ray scattering (SAXS) measurements were performed at beamline I911-SAXS (MAX IV Laboratory, Lund, Sweden) (Labrador et al., 2013). The samples were placed into quartz capillaries (ID $1.0 \mathrm{~mm}$ ) and subjected to a flux of $5 \cdot 10^{10}$ photons/s. The size of the beam were $0.3 \times 0.3 \mathrm{~mm}^{2}$ and the wavelength $0.91 \AA$. The exposure time was $100 \mathrm{~s}$ for each sample and the sample to detector distance was $1889.3 \mathrm{~mm}$. Measurements were performed at $22^{\circ} \mathrm{C}$ and corrected for background (water). Data were collected using a PILATUS 1M detector (Dectris Ltd., Baden, Switzerland) and was analyzed using the Bli911-4 GUI software version 4.12. The LC structures were identified according to Bragg peak spacings (Hyde, 2001).

\subsection{Cryogenic transmission electron microscopy}

Cryogenic transmission electron microscopy (Cryo-TEM) specimens were prepared in a controlled environment vitrification system kept at $25^{\circ} \mathrm{C}$ with humidity close to saturation. A small amount of the sample was placed onto a carbon-coated holey polymer film supported by a copper grid, gently blotted with a filter paper to form a thin liquid film $(10-500 \mathrm{~nm})$, and immediately plunged into liquid ethane at $-180{ }^{\circ} \mathrm{C}$. The sample grid was then transferred (kept at liquid nitrogen temperature) into a Zeiss LIBRA-120 transmission electron microscope (Carl Zeiss, Oberkochen, Germany) operated at $80 \mathrm{kV}$ in zero-loss bright-field mode. The samples were imaged 24-48 hours after addition of peptide to the particles and after 7 weeks of storage at room temperature. Images were recorded under low dose conditions with a TRS slow scan CCD camera system (TRS GmbH, Germany) and iTEM software (Olympus Soft Imaging Solutions $\mathrm{GmbH}$, Germany) using an underfocus of 1-3 $\mu \mathrm{m}$ was to enhance contrast. 


\subsection{In vitro assays}

\subsubsection{Microorganisms}

Microorganisms used were Staphylococcus aureus, reference strain ATCC 25923, methicillin-resistant S. aureus (MR S. aureus) clinical strain No. 0702E0196, Pseudomonas aeruginosa, reference strain ATCC 27853, ATCC PA01 and clinical strain No. 0704C0134, Escherichia coli, reference strain ATCC 25922, and ESBL E. coli, clinical strain 9007550201, and Acinetobacter baumannii, AYE reference strain ATCC BAA-1710.

\subsubsection{Minimum inhibitory concentration}

The MIC of pure peptides and peptide loaded LCNPs was performed using the broth microdilution method (Boge et al., 2016; Umerska et al., 2016a). Microorganism density was adjusted to approximately $3.3 \cdot 10^{6}$ colony forming units (CFU)/mL (for S. aureus) or to $0.5 \mathrm{McFarland}$ standards, approximately $1.5 \cdot 10^{7} \mathrm{CFU} / \mathrm{mL}$ (P. aeruginosa, E. coli, A. baumannii) using brain heart infusion broth (BHI) (bioMérieux, France) for AP114 containing formulations or 1\% BHI in water for DPK-060 and LL37 containing formulations. Serial two-fold dilutions of the tested AMP loaded LCNP samples in BHI or $1 \% \mathrm{BHI}$ in water were prepared in a 96 -well plate to obtain the desired concentration range. The MIC was defined as the lowest concentration of the sample that completely inhibited the growth of the bacteria as detected by the unaided eye. A difference of more than one dilution is necessary to claim that there is a significant difference between two samples (Umerska et al., 2016a; Valcourt et al., 2016).

\subsubsection{Time-kill assay}

Time-kill assay was performed as previously described (Boge et al., 2016). Briefly, $20 \mu \mathrm{L}$ inoculum of approximately $3.3^{*} 10^{4} \mathrm{CFU} / \mathrm{ml}$ prepared in BHI (for AP114 samples) or $1 \% \mathrm{BHI}$ in water (for DPK060 and LL37 samples) was added to the tested sample in a total volume of $2 \mathrm{~mL}$ and incubated at $37^{\circ} \mathrm{C}$. A $100 \mu \mathrm{L}$ aliquot was withdrawn from each test tube after $0,3,6$ and 24 hours and delivered onto the agar plates. Serial 100 -fold dilutions were prepared in distilled water when necessary. The agar plates were incubated for 24 hours at $37^{\circ} \mathrm{C}$, and the colonies were counted.

\subsubsection{Proteolysis}

The peptides and peptides post-loaded on cubosomes (total amount of $2 \mu \mathrm{g}$ peptide) were incubated for 6 hours at $37^{\circ} \mathrm{C}$ in $10 \mathrm{mM}$ Tris buffer $\mathrm{pH} 7.4$ together with $0.2 \mu \mathrm{g}$ Pseudomonas aeruginosa elastase (PE) (261.0 units/mg, BioCol $\mathrm{GmbH}$, Potsdam, Germany), or $0.4 \mu \mathrm{g}$ human neutrophil elastase (HNE) (20.0 units/mg, Calbiochem, La Jolla, USA) in a volume of $15 \mu \mathrm{L}$. The samples were placed in the wells of $10-20 \%$ precast Tris-Tricine sodium dodecyl sulfate polyacrylamide (SDS-PAGE) gels. Peptide degradation was visualized after electrophoresis using coomassie brilliant blue as staining.

\subsubsection{Radial diffusion assay}

Radial diffusion assay were performed on the formulations and after incubation with elasteses (PE and HNE). Detailed methodology is described elsewhere (Pasupuleti et al., 2008). An amount of $4 \cdot 10^{6}$ CFU was added to an underlay agarose gel casted in $85 \mathrm{~mm}$ petrii dishes and $4 \mathrm{~mm}$ diameter wells were punched after solidification. An amount of $6 \mu \mathrm{L}$ of the samples was added to each well and the plates were incubated at $37^{\circ} \mathrm{C}$ for 3 hours. The underlay gel was thereafter covered with molten overlay agarose gel and incubated at room temperature overnight. The antimicrobial activity of samples was visualized as a clear zone around each well. The results from these experiments are 
presented as mean diameters of the clear zones formed for the different peptide samples. Each experiment was repeated at least 4 times.

\subsubsection{Scanning electron microscopy}

For SEM, bacteria were incubated at the same cell concentrations as for the time kill assays and samples were taken after 10 hours incubation. Bacteria were adsorbed onto poly-L-lysine coated 1.1 $\mathrm{cm}$ glass slides for 1 hour. Bacteria suspension was then gently aspirated and replaced by fresh phosphate buffered saline (PBS) pH 7.4 twice. Then, fixative solution (2\% glutaraldehyde and $2 \%$ paraformaldehyde in PBS) was added and allowed to stand overnight at room temperature. Following day, samples were rinsed with PBS and dehydrated using an ethanol series of 25/50/70/95/100\% (20 min in each solution). Thereafter the samples were desiccated using hexamethyldisilizane:ethanol ratios of 1:1 and 1:0 (45 $\mathrm{min}$ in each solution, last step done twice), and allowed to dry overnight in a fume hood. Samples were sputtered with platinum and transferred into the scanning electron microscope (SEM) and the cells were imaged using a Jeol JSM-6301F scanning microscope (JEOL Ltd, Japan) operated at $3 \mathrm{kV}$. 


\section{Results}

\subsection{Characterization of AMP-loaded cubosomes}

The formed cubosomes had a mean hydrodynamic diameter of $191.7 \pm 12.0 \mathrm{~nm}$ with a narrow particle size distribution (PDI $0.05 \pm 0.02$ ) and $\zeta$-potential of $-24.8 \pm 3.4 \mathrm{mV}$, in agreement with previous literature (Barauskas et al., 2005; Vandoolaeghe et al., 2006). Figure $1 \mathrm{~A}$ show the change in particle size before and after a heat-treatment cycle. Dry content was typically $44 \mathrm{mg} / \mathrm{mL}$, which is equal to $98 \%$ of theoretical dry content. Peptide association with cubosomes was characterized by HPLC measurements (Figure $1 \mathrm{~B}$ ), followed by $\zeta$-potential using peptide concentration scans (Figure 2 A) and through CD measurements (Figure 2 B). Peptide association onto the cubosomes was studied at two different particle concentrations and ionic strengths. Samples containing $5 \mathrm{mg} / \mathrm{mL}$ particles (no added $\mathrm{NaCl}$ ) showed an association efficacy of 7-8\% for the peptides AP114 and DPK-060. Interestingly, LL-37 showed a much higher degree of association, with more than $60 \%$ of added peptide associated to the particles. When the concentration of cubosomes was doubled $(10 \mathrm{mg} / \mathrm{mL})$ it resulted in more than doubled AMP associated to the particles in case of AP114 and DPK-060. LL-37 showed roughly the same association efficacy for both cubosome concentrations. A higher ionic strength $(150 \mathrm{mM} \mathrm{NaCl})$ resulted in a significant stronger association of all peptides to the cubosomes.
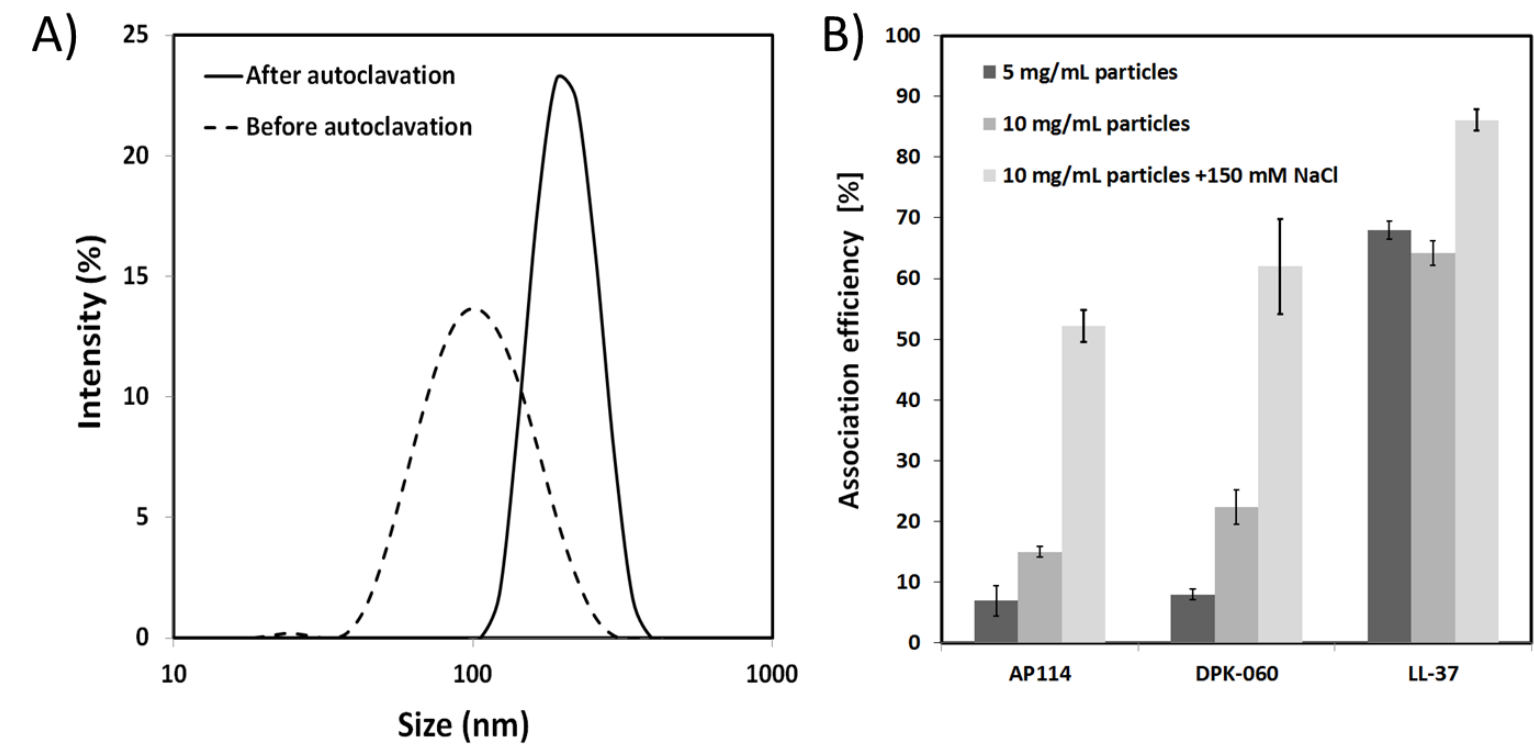

Figure 1. Particle size distributions (diameter) before and after a heat-treatment cycle (A) and association of AMPs AP114, DPK-060 and LL-37 on cubosomes, quantified by HPLC (B) $(n=3)$. The adsorption of AP114 and DPK-060 was found to be strongly affected by both the particle concentration and ionic strength. AMP concentration was $100 \mu \mathrm{g} / \mathrm{mL}$ for all samples. Samples were prepared in $5 \mathrm{mM}$ sodium acetate buffer at pH 5.5.

The presence of the positively charged AMP onto the surface of cubosomes was further indicated by the increase in $\zeta$-potential upon peptide addition, as displayed in Figure $2 \mathrm{~A}$. The $\zeta$-potential increased upon addition of all AMPs and the peptide LL-37 resulted in the largest change. The $\zeta$ potential was always lowest (in absolute values) at lowest peptide concentrations and turned higher at higher peptide concentrations. 
The secondary structure of the peptides was examined with CD and data is presented in Figure $2 \mathrm{~B}$. None of the pure AMPs displayed any distinct signs of ordered secondary structure and were most likely in a random coil conformation. Results for AP114 and LL-37 showed a clear change in CD spectra with minima approximately at $225 \mathrm{~nm}$, characteristic for a transition into $\alpha$-helix (Sjögren and Ulvenlund, 2005) in the presence of the cubosomes particles.
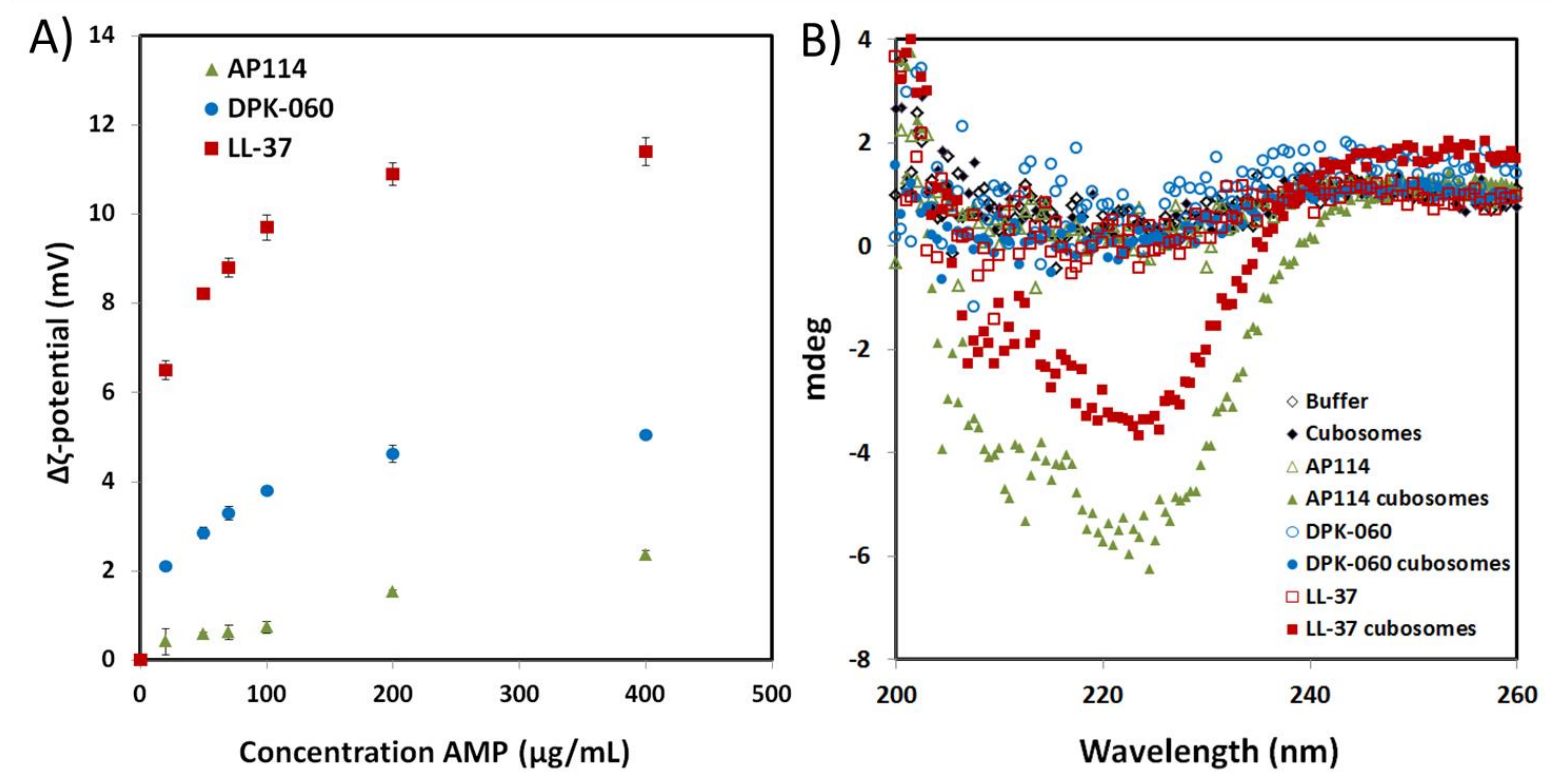

Figure 2. Particle $\zeta$ - potential as function of concentration of AMP (A) and peptide secondary structure measured by CD (B). A clear increase in $\zeta$-potential was observed upon addition of the AMPs, indicating presence on the particle surface. A change in secondary structure was observed AP114 and LL-37 in presence of cubosome particles. Samples were measured in $5 \mathrm{mM}$ sodium acetate buffer $\mathrm{pH} 5.5$.

The release of AMP from the cubosomes was monitored by dialysis in $5 \mathrm{mM}$ sodium acetate buffer $(\mathrm{pH} 5.5)$ with or without physiological salt concentration $(150 \mathrm{mM} \mathrm{NaCl})$. Results from the flourescamine assay are presented in Figure 3 and show that the peptide release from the cubosomes was drastically reduced at the higher ionic strength. At the low ionic strength, the release was in the same order as for the pure peptide references, and appeared very quick during the first 6 hours. LL-37 loaded cubosomes displayed a very quick and high release in the pure buffer, close to $100 \%$ release over 24 hours. It was found that the co-polymeric stabilizer (P407), present in the cubosome samples, accelerated the release of LL-37 through the dialysis membrane at low ionic strength of the buffer. More details can be found in the Supplementary material Figure S4. 

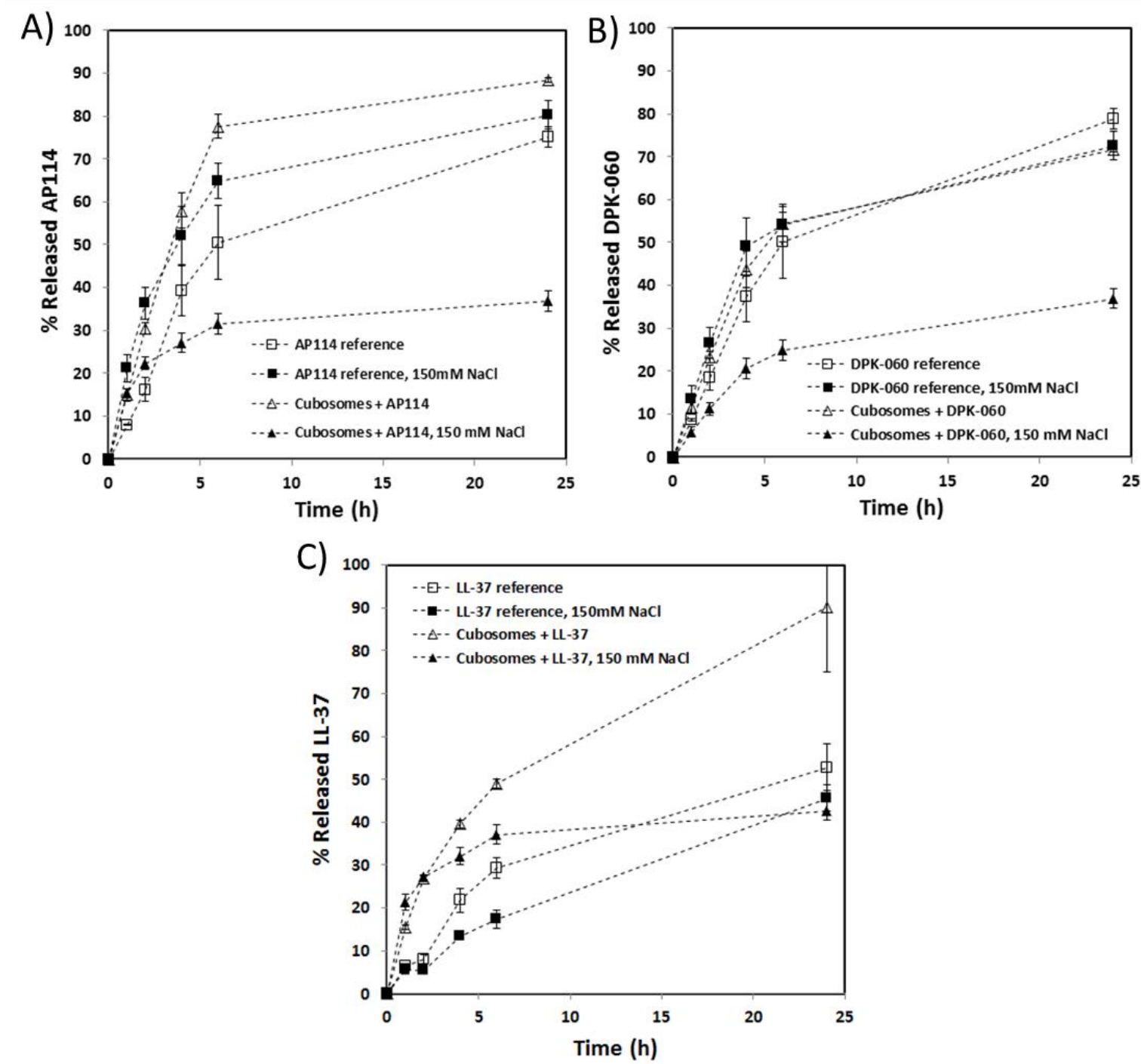

Figure 3. Release of AMP associated to cubosomes. References with pure AMP as well as loaded onto cubosomes were dialyzed; AP114 (A), DPK-060 (B) and LL-37 (C). Release of AP114 and DPK-060 from cubosomes appeared to be slower at higher ionic strength. Peptide concentration was $100 \mu \mathrm{g} / \mathrm{mL}$ and cubosome concentration $10 \mathrm{mg} / \mathrm{mL}$. Each experiment was repeated twice.

The LC structure and appearance of the AMP loaded cubosomes were investigated using SAXS (Figure 4) and Cryo-TEM (Figure 5). SAXS diffractograms displayed 3 Bragg diffraction peaks, for both reference and particles loaded with any of the AMPs, with spacing ratios of $2^{1 / 2}: 4^{1 / 2}: 6^{1 / 2}$. These reflections can be indexed as (110), (200) and (211), respectively, characteristic for the cubic phase space group Im3m (Barauskas et al., 2005; Hyde, 2001). Calculated lattice parameter for the reference system was $129.2 \AA$, and data revealed that the AMPs had minor influence on the lattice parameter within 48 hours after sample preparation. 


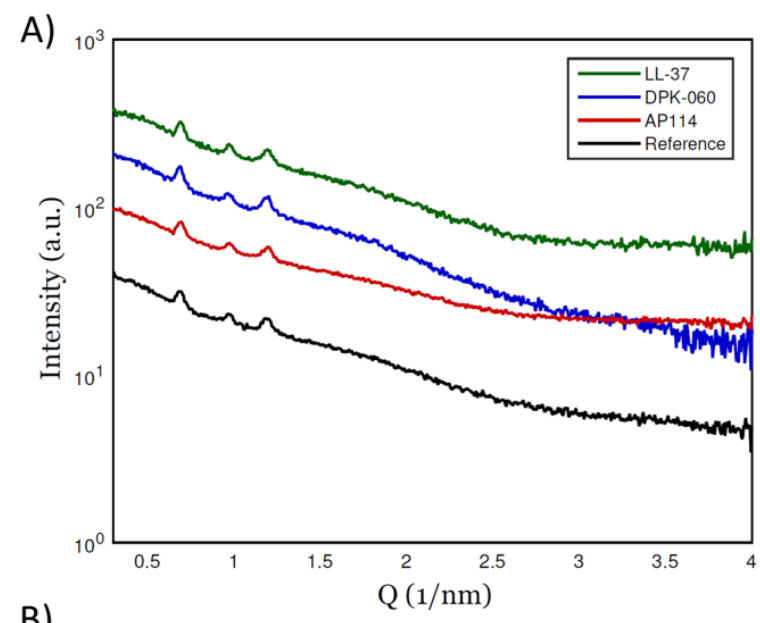

B)

\begin{tabular}{ccc}
\hline AMP & Phase & Lattice parameter a $(\AA)$ \\
\hline- & $\operatorname{Im} 3 \mathrm{~m}$ & 129.2 \\
AP114 & $\operatorname{Im} 3 \mathrm{~m}$ & 128.3 \\
DPK-060 & $\operatorname{Im} 3 \mathrm{~m}$ & 129.5 \\
LL-37 & $\operatorname{Im} 3 \mathrm{~m}$ & 129.3 \\
\hline
\end{tabular}

Figure 4. SAXS diffractograms of AMP loaded LCNPs (A) and corresponding LC phases with calculated lattice parameters (B). Peptide concentration was $100 \mu \mathrm{g} / \mathrm{mL}$ and particle concentration was $10 \mathrm{mg} / \mathrm{mL}$. Only samples with the higher particle concentration were analyzed in order to get higher intensity of the scattering data. Samples were prepared in 5 $\mathrm{mM}$ sodium acetate buffer at $\mathrm{pH} 5.5$ and analyzed within 48 hours after preparation.

Cryo-TEM imaging was performed in order to study if the AMP had any influence on particle morphology, see Figure 5. Samples were imaged within 48 hours after sample preparation and after 7 weeks of storage at room temperature. All samples contained cubosomes of uniform size and shape, well in agreement with the cubic Bragg diffraction peaks found in the SAXS analysis and size obtained from the DLS data. Surprisingly, the samples did also contain a substantial fraction of vesicles slightly larger than the cubosomes, but also these of very uniform size. No apparent difference between the samples was observed at the first imaging and after the 7 weeks of storage for the reference and AP114 and DPK-060 loaded cubosomes. LL-37 loaded cubosomes appeared less cubic shaped and surrounded by more lamellar structures after 7 weeks storage, compared to the first imaging. 


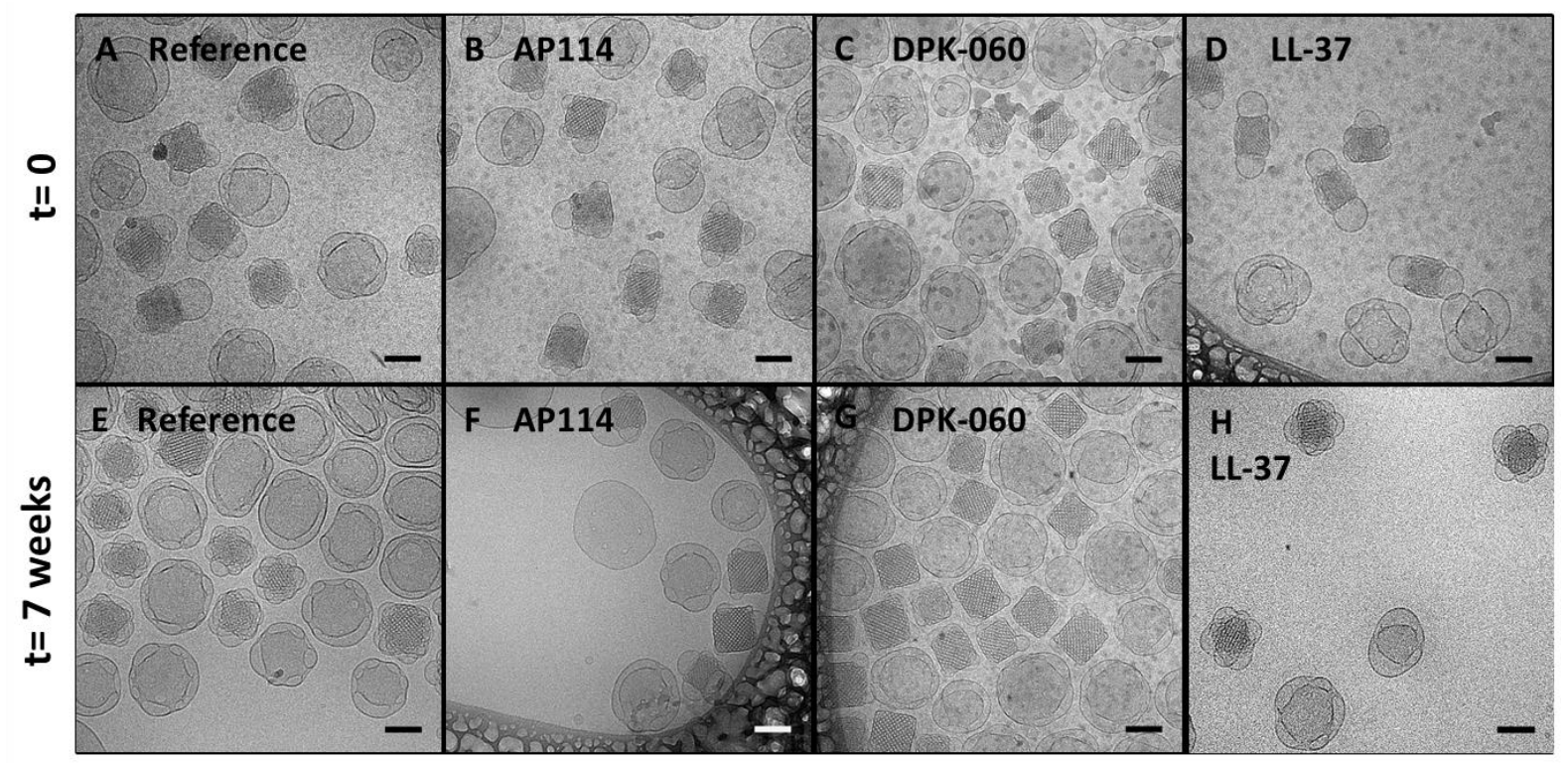

Figure 5. Representative cryo-TEM images of samples containing $10 \mathrm{mg} / \mathrm{mL}$ particles and $100 \mu \mathrm{g} / \mathrm{mL}$ AMP. Samples were prepared in $5 \mathrm{mM}$ sodium acetate buffer at pH 5.5 imaged within 48 hours after preparation and after 7 weeks storage at $22 \pm 1^{\circ} \mathrm{C}$. Scale bar equals $100 \mathrm{~nm}$.

\subsection{In vitro antibacterial effect}

The in vitro antibacterial properties of the formulations were investigated using MIC test (Table 3) and time-kill assay (Figure 6). The effect on the bacterial cells was visualized using SEM-imaging (Figure 7). In most cases, the MIC values for AP114 and DPK-060 loaded onto LCNPs showed a similar antimicrobial effect, as the unformulated peptide. Interestingly, DPK-060 loaded particles appeared to be very effective in inhibiting the growth of $S$. aureus and MR S. aureus strains, as seen by the 1-2 dilutions lower MIC values than those for the unformulated peptide. No apparent differences concerning the two different particle concentrations (i.e. $5 \mathrm{mg} / \mathrm{mL}$ and $10 \mathrm{mg} / \mathrm{mL}$ ) were observed. Particles loaded with LL-37 displayed a reduction in its broad spectrum antimicrobial activity, in contrast to unformulated peptide that did not inhibit the growth of $S$. aureus at $16 \mu \mathrm{g} / \mathrm{mL}$. However, LL-37 formulations showed activity against Gram-negative bacteria comparable to that of unformulated LL-37. As for the AP114 and DPK-060 samples, no difference between the two particle concentrations was observed for LL-37 containing samples. Particles without AMP did not show any antibacterial effect.

Table 3. MIC values for unformulated peptide (UF) and for samples containing 5 (A) and 10 (B) $\mathrm{mg} / \mathrm{mL}$ particles. Particles loaded with AP114 and DPK-060 showed a preserved antimicrobial effect while samples that contained LL-37 displayed a reduced effect. Peptide AP114, known to be only active against gram-positive (+) bacteria, was not tested on strains gram-negative (-) strains.

\begin{tabular}{lcccccccccc}
\cline { 2 - 10 } & \multicolumn{10}{c}{ MIC values $(\boldsymbol{\mu g} / \mathbf{m L})$} \\
\cline { 2 - 11 } & \multicolumn{3}{c}{ AP114 } & \multicolumn{3}{c}{ DPK-060 } & \multicolumn{3}{c}{ LL-37 } \\
\hline Bacterial strain & UF & A & B & UF & A & B & UF & A & B \\
S. aureus (+) & 8 & $8-16$ & $8-16$ & 4 & $1-2$ & $1-2$ & $8-16$ & $>16$ & $>16$ \\
MR S. aureus (+) & 4 & $2-4$ & 4 & 4 & $1-2$ & 2 & $8-16$ & $>16$ & $>16$ \\
P. aeruginosa (-) & - & - & - & 8 & $8-16$ & $8-16$ & $8-16$ & $8-16$ & $8-16$ \\
P. aeruginosa clinical strain (-) & - & - & - & 16 & 8 & 8 & $8-16$ & $8-16$ & $8-16$ \\
E. coli (-) & - & - & - & 8 & 4 & 4 & 16 & $8-16$ & $8-16$ \\
ESBL E. coli clinical strain (-) & - & - & - & $4-8$ & $2-4$ & $2-4$ & 16 & $\geq 16$ & $\geq 16$ \\
A. Baumannii (-) & - & - & - & $4-8$ & $8-16$ & 16 & 16 & $\geq 16$ & $\geq 16$ \\
\hline
\end{tabular}


The bactericidal effect against S. aureus and E. coli was measured by time-kill assays at relevant AMP concentrations, selected from formulations showing lower or preserved MIC-values. Only samples with the higher particle concentration $(10 \mathrm{mg} / \mathrm{mL})$, and in turn higher peptide association efficacy, were evaluated. Particles loaded with AP114 (Figure 6 A) showed a very similar S. aureus killing at a concentration of $16 \mu \mathrm{g} / \mathrm{mL}$ compared with unformulated peptide. However, after an initial growth inhibition during the first 6 hours at $8 \mu \mathrm{g} / \mathrm{mL}$ AP114, for both reference and AP114 loaded cubosomes, an increase in the CFU number was observed for the latter. Particles loaded with DPK060 (Figure 6 B) showed similar time-kill profile as unformulated DPK-060 against $S$. aureus at $4 \mu \mathrm{g} / \mathrm{mL}$. Interestingly, at a concentration of only $2 \mu \mathrm{g} / \mathrm{mL}$ the DPK-060 loaded cubosomes performed better than the unformulated peptide. The positive control (particles without peptide) showed in all cases an increase in the number of $S$. aureus bacteria, comparable to that of control (no particle or peptide), and did apparently not display any antibacterial effect.

Both unformulated and formulated peptide showed similar time kill profiles at $8 \mu \mathrm{g} / \mathrm{mL}$ of DPK-060 against $E$. coli (Figure $6 \mathrm{C}$ ), with a rapid bactericidal effect within the first hours of incubation. At lower DPK-060 concentration $(4 \mu \mathrm{g} / \mathrm{mL})$, a significant difference was observed between formulated and unformulated peptide. While DPKO60-loaded cubosomes maintained their bactericidal effect after 24 hours, a growth of bacteria was observed for the unformulated peptide. Interestingly, cubosomes showed inhibitory effect against E. coli during the first 3 hours of incubation. No inhibitory effect was observed after 24 hours, and the number of viable cells was the same as for the control (no peptide or particles). Particles loaded with LL-37 (Figure 6 D) showed a rapid bactericidal effect at $16 \mu \mathrm{g} / \mathrm{mL}$ against $E$. coli, similar to unformulated peptide. At a lower concentration (8 $\mu \mathrm{g} / \mathrm{mL}$ ) did the LL-37 loaded cubosomes show a greater bacterial killing than the unformulated peptide. However, the bactericidal effect (for both LL-37 loaded cubosomes and reference) declined after 6 hours, and the number of cells started to increase. Time-kill curves for lower AMP concentrations are found in the Supplementary material Figure S1. 

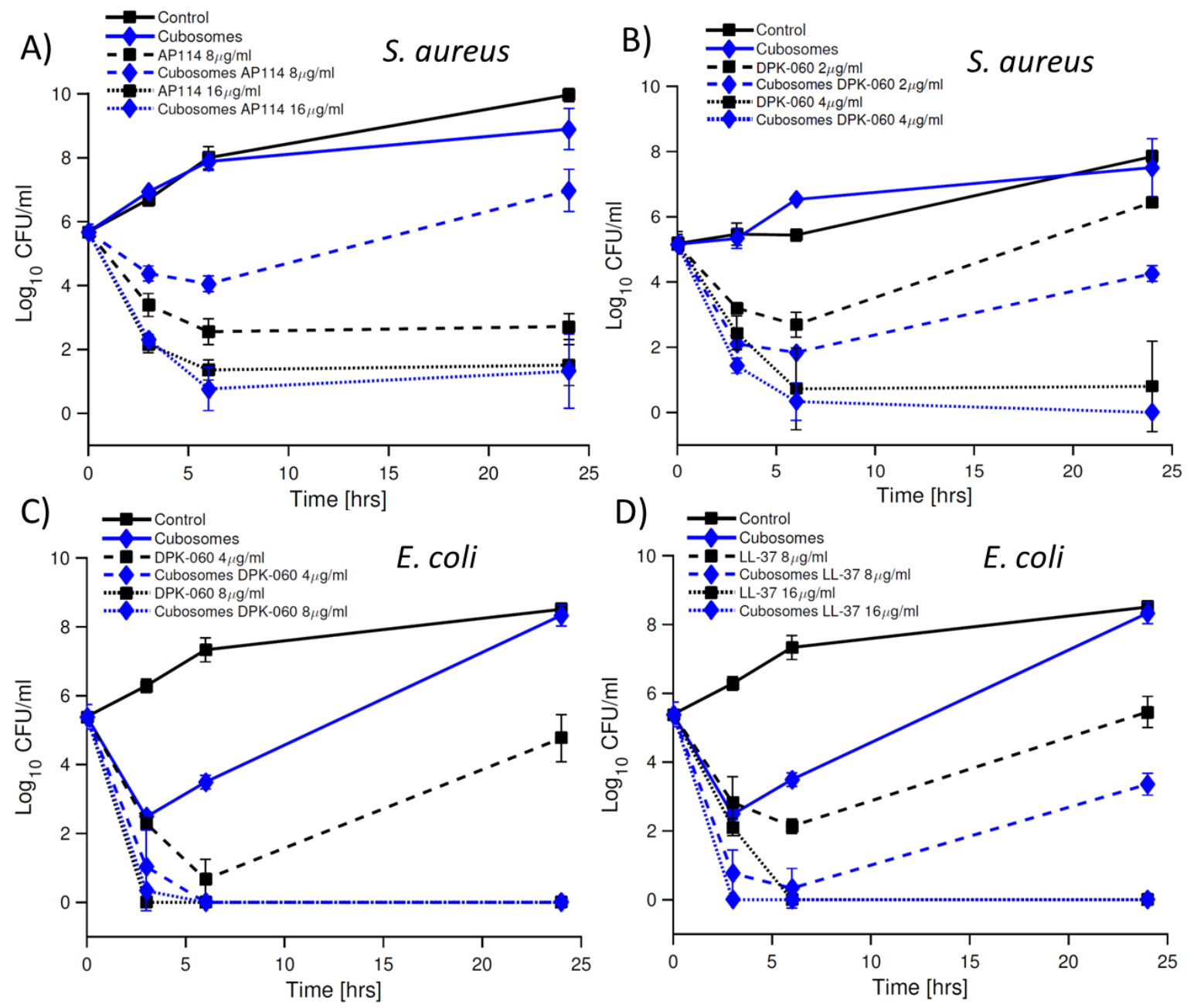

Figure 6. Time-kill curves for cubosomes $(10 \mathrm{mg} / \mathrm{mL}$ ) loaded with AP114 (A), DPK-060 (B and C) and LL-37 (D).

In order to visualize the effect the AMPs had on cell morphology, bacterial samples (S. aureus, MR S. aureus and E. coli) were fixated and dehydrated to enable SEM-imaging. Bacteria were cultured in the same way as described for the time-kill assay. Figure $7 \mathrm{~A}-\mathrm{F}$ displays images of $S$. aureus viewed after $10 \mathrm{~h}$ incubation with samples containing AP114 and DPK-060. Both pure peptides and peptideparticle formulations displayed a drastic reduction in bacteria density. Bacterial cells subjected to any of the two peptides usually showed a rough surface morphology or deformations. Sometimes totally lyzed (Figure $7 \mathrm{C}$ ) and "raisin"-like cells (Figure $7 \mathrm{~F}$ ), as well as cells with cracks and holes, could be observed. Reference bacterial cells were found in large clusters, and displayed a smoother surface morphology without any apparent damage. Moreover, the particles on their own were found not to influence the morphology of the bacteria. 


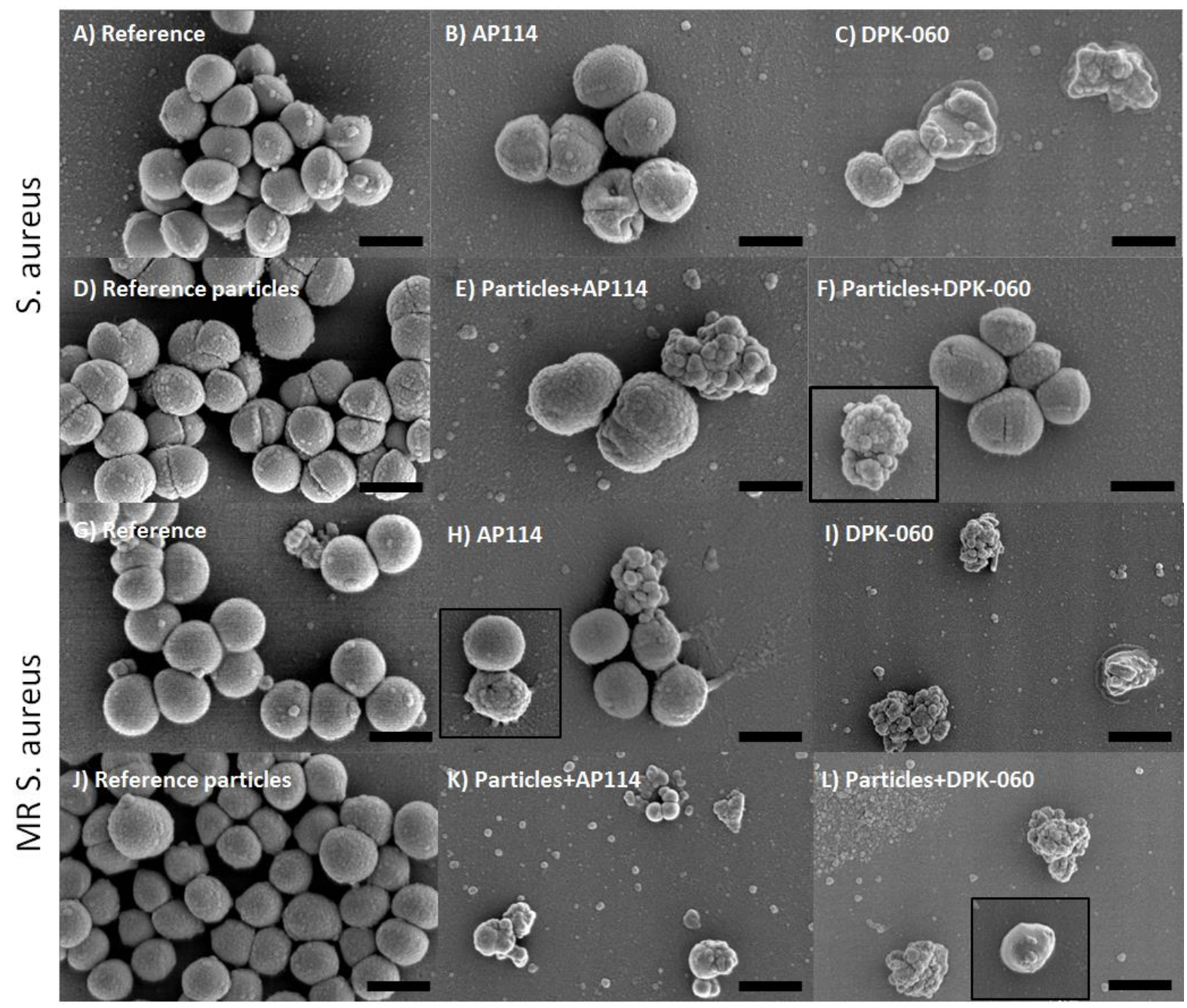

Figure 7. SEM images S. aureus (A-F) and MR S. aureus (G-L) after 10 hours incubation time. Clear cell damage was observed when the cells were subjected to any of the AMPs or AMP-loaded cubosomes. Scale bar equals $\mathbf{1} \boldsymbol{\mu m}$.

Images of untreated MR S. aureus (Figure $7 \mathrm{G}$ ) had a smooth surface, comparable to $S$. aureus (Figure 7 A). As for the S. aureus bacterial cells, MR S. aureus bacteria subjected to AP114 and DPK-060 displayed very few bacteria, and of those were many found to be damaged. Again, bacteria treated with AMP displayed rough surface with blisters (Figure $7 \mathrm{H}$ and $\mathrm{K}$ ) or totally lyzed cells (Figure $7 \mathrm{I}$ and L). No clear difference was found between pure AP114 and DPK-060 and their particle loaded analogues. The particles without any peptide did not influence the morphology of the bacteria. E. coli reference cells, not subjected to any AMP, appeared wrinkled and slightly damaged while viewed in the microscope. Images are found in the Supplementary material Figure S2.

\subsection{Proteolytic stability and effect after proteolysis}

The proteolytic stability of the pure AMPs and post-loaded on cubosomes were investigated using the two clinically relevant enzymes PE and HNE. After incubation with the elastases the samples were separated by size, using gel-electrophoresis. The data is presented in Figure 8 and showed that AP114 and DPK-060 (both references and post-loaded on cubosomes) were not degraded by any of the two enzymes. However, pure LL-37 was found to be degraded by both PE and HNE, as seen by the fussy bands in Figure $8 \mathrm{~B}$ and C. Interestingly, LL-37 post-loaded on cubosomes was shown to protect the peptide against attack from both PE and HNE. 


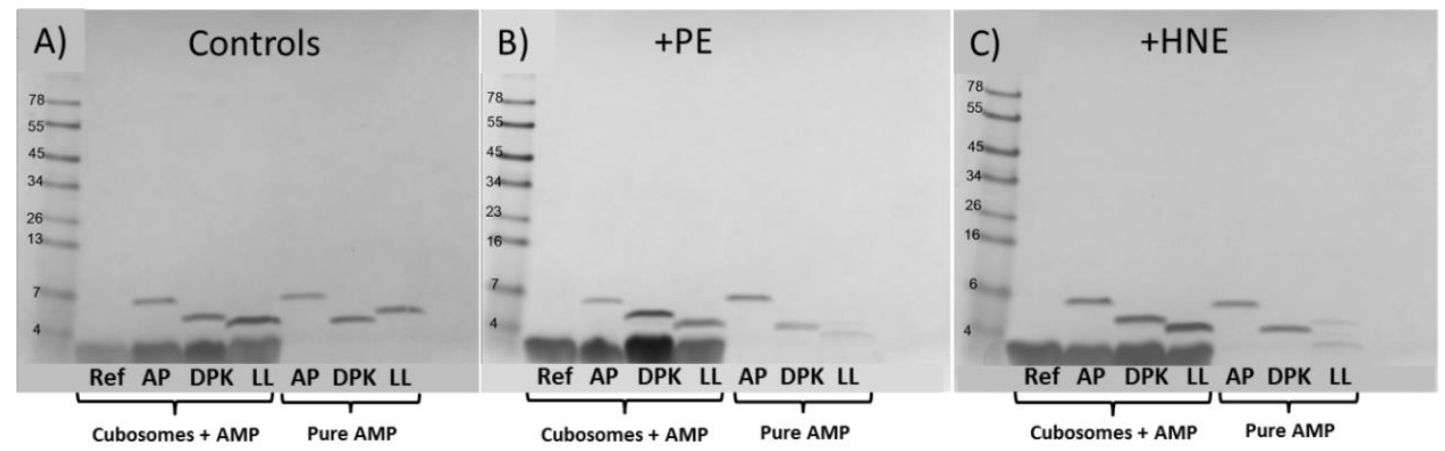

Figure 8. Proteolysis of post-loaded cubosomes; control samples without any enzyme (A), after incubation with PE (B) and HNE (C). Results showed that AP114 and DPK-060 were stable in presence of the enzymes (strong bands), while LL-37 was degraded (fuzzy bands). LL-37 was found to be protected against the proteolytic attacks if the peptide was associated to cubosomes. Ref= pure cubosomes, AP=AP114, DPK=DPK-060 and LL=LL-37.

RDA was used to investigate the antibacterial effect of post-loaded cubosomes as they were (controls) and after proteolysis with PE and HNE. The results are shown in Figure 9. As observed in the MIC-tests, it was found that pure AP114 (control) showed good bacterial killing against S. aureus. Moreover, it was found that DPK-060 and LL-37 killed both S. aureus, P. aeruginosa and E. coli, in line with MIC and time-kill assays. Control cubosomes loaded with AP114 and LL-37 displayed a similar effect as for pure peptide. DPK-060 loaded cubosomes performed slightly poorer than pure DPK-060, a phenomenon not expected by the MIC and time-kill assays. Moreover, DPK-060 loaded cubosomes did maintain its broad spectrum activity after incubation with PE (S. aureus, P. aeruginosa and E. coli) compared to unformulated peptide showing activity only against $S$. aureus and $P$. aeruginosa. A significant increase in bactericidal effect was observed for LL-37 loaded cubosomes after proteolysis, compared to the pure LL-37 reference. Example of raw-data images of RDA can be found in the Supplementary material Figure S3.

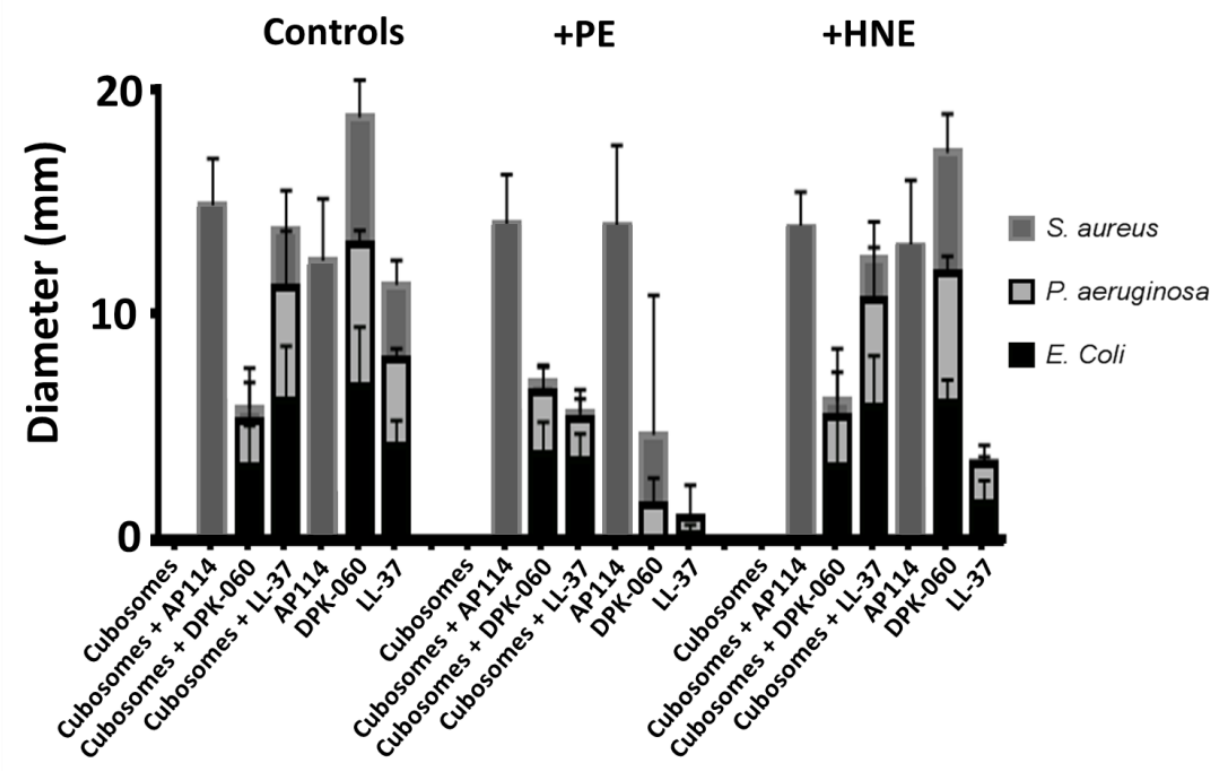

Figure 9. Bactericidal effect determined by RDA unformulated reference peptides and peptides post-loaded cubosomes after incubation with PE or HNE on SA, PA and EC. Larger diameter corresponds to more effective radial diffusion of the $A M P$, and in turn bacterial killing. Data is presented as mean + standard deviation ( $n=5$ for $E C$, and $n=4$ for PA and SA). 


\section{Discussion}

\subsection{Characterization of AMP-loaded cubosomes}

The adsorption of AMP to cubic LCNPs was found to vary a lot among the peptides included in this study. According to the results, there seems to be a combination of factors influencing the adsorption. The association efficacy data for AP114 and DPK-060 is comparable to the adsorption of somatostatin, 10-20\% (molecular weight $1638.1 \mathrm{~g} / \mathrm{mole}$ and net charge +2) onto soy phosphatidylcholine/glycerol dioleate/Tween80 based LCNPs (Cervin et al., 2009). Moreover, adsorption was more than doubled if the particle concentration was doubled, indicating that there is a sensitive equilibrium between adsorbed and non-adsorbed peptide. In case of LL-37 that has properties in between the peptides AP114 and DPK-060, in terms of percentage of hydrophobic amino acids and net charge, it was found to have strongest affinity to the particles. The concentration of particles in this case did surprisingly not influence the quantity of adsorbed peptide, which could be expected for an increase of the accessible particle surface available for peptide adsorption. This indicates that already at the lower particle concentration the accessible surface area for peptide adsorption was in excess. Thus, did not an increase in particle concentration influence the amount of adsorbed LL-37. The combination of having low positive net charge, large fraction hydrophobic residues and high molecular weight, did not favor a strong adsorption in case of AP114. One could believe that electrostatic interactions would be the most important factor influencing the adsorption. However, this hypothesis does not hold in case of DPK-060, that comprises the highest positive net charge $(+8.5)$, but still showed lower adsorption compared to LL-37 $(+6.3)$. This indicates that the distribution and location of the hydrophobic and charged amino acids (the amphiphilicity) also plays a role in the adsorption. All peptides displayed a significant increase in association efficacy at physiological salt concentration $(150 \mathrm{mM} \mathrm{NaCl})$, indicating that electrostatic interactions are of great importance for the adsorption. The strong interaction of LL-37 with cubosomes was also confirmed by the CD measurements, showing an increase in peptide adapting $\alpha$-helix secondary structure, as a result of interaction with the cubosomes. These findings are in good agreement with data reported previously for adsorption of LL-37 onto vesicles, also showing increased helicity upon peptide adsorption (Dürr et al., 2006). Moreover, the change from a random coil conformation to helical structure with a radial amphiphilicity may also favor a more dense packing of the LL-37 peptide onto the cubosomes. Recent studies do also indicate that $C D$ is a useful tool for characterizing the loading efficacy of AMPs in cubosome carriers (Meikle et al., 2017).

Interestingly, the trend in peptide association measured by HPLC (LL-37>DPK-060>AP114) was also observed by the $\zeta$-potential measurements. A big change in $\zeta$-potential was found to be proportional to a high association of peptide to the particles. Similar trends in peptide loading and particle $\zeta$ potential has previous been reported for the AMPs salmon calcitonin, AP114 and polymyxin B onto lipidic nanocapsules (Umerska et al., 2016b). Moreover, it was found that an increased particle to AP114-ratio, gave higher association efficacy, in good agreement with our findings.

The release of AMP was found to be significantly slower (and lower) from the cubosomes at physiological ionic strength, in line with the peptide association measurements displaying higher adsorption. When the ionic strength was increased, screenings of the electrostatic interactions occur due to lowered Debye length. If charges on the peptides give rise to peptide-peptide repulsions, screening of those could ease a denser packing of molecules on the cubosome surface, also resulting in a higher peptide loading and slower release. At low ionic strength (pure buffer with no added 
$\mathrm{NaCl})$ the release profiles of AP114 and DPK-060 were roughly the same as for the pure peptides, indicating that only non-adsorbed peptide is transferred over the dialysis barrier.

SAXS analysis of the particles LC structure revealed no phase change from the cubic Im3m structure upon addition of AMP. This finding supports the hypothesis that the peptides are only adsorbing onto the particles outer surface, and do not migrate further into the folded lipid bilayers. Both AP114 and DPK-060 have previously shown to induce phase transitions, at the same lipid/peptide-ratio, while formulated in LC GMO/water systems (Boge et al., 2016). LL-37, at very high loadings, in GMO dispersions has previously shown to induce transition from cubosomes to vesicles and micelles (Gontsarik et al., 2016). The cryo-TEM images of LL-37 loaded cubosomes 7 weeks after preparation did also indicate a transition of the cubosome particles into more vesicle-like structures. This further supports that a strong interaction between the cubosomes and LL-37 is taking place. The calculated lattice parameter for the $1 \mathrm{~m} 3 \mathrm{~m}$ space group did not differ significantly among the AMP loaded samples in this study, indicating that the AMPs were only localized on the outer surface of the particles.

As expected, the heat-treatment cycle of the ultra-sonicated LCNP dispersion made the particle size distribution much narrower, as observed by DLS, and was also confirmed by the cryo-TEM images. Surprisingly, cryo-TEM images also showed that the cubosome particles co-existed with various vesicles. However, the number of small unilamellar vesicles usually present in ultra-sonicated dispersions was drastically reduced. An optimization of the autoclavation time and cooling of the sample afterwards could influence of the particle appearance. Another way to reduce the fraction of vesicles is to optimize the lipid to stabilizer ratio and preparation procedure. This was recently performed for the phytantriol/F127 system, using cryo-TEM images to quantify vesicle fraction, and results showed that the lipid:F127 ratio strongly influenced the vesicle fraction (Akhlaghi et al., 2016).

\subsection{In-vitro antibacterial effect}

Post-loaded DPK-060 cubosomes appeared to be more effective in killing of S. aureus and E. coli than the unformulated peptide, as indicated by the results of MIC and time kill assays. This effect can be considered as synergistic. Similar effect has already been described for DPK060 pre-loaded cubosomes against E. coli (Boge et al., 2016). Cubosomes post-loaded with LL-37 showed a very interesting behavior, by changing the spectrum of activity of LL-37. Formulated LL-37 showed decreased activity against Gram-positive $S$. aureus, but well preserved or even improved activity against Gram-negative bacteria. The differences in bacterial cell wall structure between grampositive and gram-negative bacteria may also influence the bactericidal properties of the LL-37 loaded cubosomes. Delivery or release of the peptide might not be sufficient onto the thick outer peptidoglycan layer from the cubosomes, in case of gram-positive bacteria. Moreover, it has been shown that high degree of $\alpha$-helicity of LL-37 promotes its antibacterial activity on both Grampositive and Gram-negative bacteria (Johansson et al., 1998). However, our findings show preserved activity only against Gram-negative strains, even though the $\alpha$-helicity increased upon cubosome association. High affinity of the LL-37 peptide to these particles may retard its release, resulting in decreased amount of free peptide capable of exerting antibacterial activity. A similar decrease in the broad spectrum activity of LL-37 was previously shown for peptide loaded inside GMO-based LCNPs (Boge et al., 2016). Another study showed that LL-37 loaded in GMO-based dispersions, at high loading (50:50 GMO:LL-37), displayed a remarkable enhancement in killing a clinical isolate of $E$. coli, 
revealed by time-kill assay (Gontsarik et al., 2016). A similar effect was found in our time kill experiments on E. coli at $8 \mu \mathrm{g} / \mathrm{mL}$ of LL-37, where the peptide loaded cubosomes performed significantly better that unformulated peptide during the first 6 hours. After 6 hours the bacteria started to increase in number again, thus indicating the LL-37 concentration was not sufficient to kill all cells.

The release experiments might provide further insight to the in vitro antibacterial effect of the formulations. The $100 \% \mathrm{BHI}$ contains roughly the same ionic strength as the buffer with $150 \mathrm{mM}$ $\mathrm{NaCl}$ and the $1 \% \mathrm{BHI}$ medium approximately mimic the $5 \mathrm{mM}$ sodium acetate buffer, used in the release experiments. The release of AMP from the cubosomes was found to be greatest during the first 6 hours, in line with the killing kinetics shown by the time-kill assays. For a majority of the AMP loaded cubosomes, the bacterial killing reached its maximum after 6 hours incubation. If the release is as low in the $100 \% \mathrm{BHI}$ media for AP114 as in the buffer with $150 \mathrm{mM} \mathrm{NaCl}$ (only $30 \%$ released peptide after 24 hours), one would probably not expect such good antimicrobial effect, if not the peptide loaded particle itself would have contributed to the bacterial killing. However, the mechanism of delivery of AMP to the bacteria remains somewhat unclear and could be studied further. The DPK-060 loaded cubosomes displayed a very similar release as for the reference peptide in the buffer with no extra salt added. One would thus expect a very similar bacterial killing in vitro, which also was the case. However, the slightly synergistic effect observed for DPK-060 loaded cubosomes on S. aureus and E. coli cannot be contributed to differences in release profiles. Data suggest it might instead come from a particle-bacteria interaction, giving rise to the mild increase in activity.

Bacterial cells subjected to pure AP114 or DPK-060, or peptide loaded cubosomes, appeared to be seriously damaged, as displayed by the SEM images, in line with previously reported images of AMP treated bacteria (Hartmann et al., 2010; Kasetty et al., 2015; Valcourt et al., 2016). The particles on their own were not found to influence the cell morphology on $S$. aureus and MR S. aureus, in line with MIC and time-kill data showing no antibacterial effect. The reason for the observed wrinkled and slightly damaged E. coli cells (images found in Supplementary material) might be because of osmotic stress during the rinsing step using PBS buffer, which ionic strength was much higher than the $1 \% \mathrm{BHI}$ growth medium used to culture these cells.

\subsection{Proteolytic stability and effect after proteolysis}

In this study it was found that LL-37 was degraded by both PE and HNE, in line with previous reported data (Braun et al., 2016). Interestingly, LL-37 loaded cubosomes were shown to protect the peptide against attack from both PE and HNE resulting in increased antibacterial effect after enzyme exposure. Previously, it was shown that the AMP melittin, adsorbed onto lipid-disks particles, was protected from proteolytic attacks of trypsin (Zetterberg et al., 2011). It was hypothesized that the polyethylene glycol (PEG) stabilizer located on the rim of the particles provided steric hindrance, blocking efficient peptide-enzyme interactions. The block copolymer PEO-PPO-PEO (P407), used as stabilizer for the cubosome particles, may possibly protect the LL-37 peptide from enzymatic degradation in a similar way. Moreover, differences in bacterial killing efficacy of DPK-060 loaded cubosomes were observed in MIC, time-kill and RDA assays. However, the difference may be attributed to different killing mechanisms or AMP delivery mechanisms. The MIC and time-kill assays were performed on planktonic bacteria, compared to the RDA where the bacteria are fixated in an agarose gel. Hence, the bacterial killing in RDA is a result of peptide and/or particle diffusion through 
the agarose gel. Interestingly the RDA showed a significant better effect of LL-37 while associated to cubosomes and exposed to PE or HNE, compared to unformulated LL-37, in agreement with the proteolysis data showing that the cubosomes protected LL-37 from proteolytic degradation.

\section{Conclusion}

This study shows that post-loading of AMPs onto cubosomes can be an effective alternative, especially for LL-37, to the more traditional pre-loading approach.. AMPs with a very pronounced amphiphilicity and high positive net charge, seems to be most suitable to adsorb onto cubosomes, such as the alpha-helical LL-37 peptide. Results showed that the peptide association was strongly influenced by the particle concentration and ionic strength. The data presented indicates that the AMPs are associating to the cubosome surface, and do not penetrate or diffuse in to the particles. Moreover, it was shown that release of the AMPs from the cubosome carriers were slowed down drastically if the ionic strength of the release media was increased to physiological condition. The antimicrobial effect of the peptide loaded cubosomes were preserved (AP114) or sometimes even slightly enhanced (DPK-060 on S. aureus and E. coli). Cubosomes loaded with LL-37 displayed a loss in its broad spectrum bacterial killing, and were found only to have activity against Gram-negative strains. This might be contributed to the very high peptide association efficacy to the particles and high degree of $\alpha$-helicity, which may influence the killing mechanism on Gram-positive bacteria, such as for S. aureus strains. Importantly, we demonstrated that the proteolytic sensitive peptide LL-37 could successfully be protected against enzymatic attacks, while associated to cubosomes, with good bactericidal effect after the proteolysis. Future work may involve modifications of the composition of the cubosomes to enhance peptide adsorption e.g. by adding negatively charged components such as fatty acids.

\section{Acknowledgment}

This research performed in this study was funded by the European Union's Seventh Framework Programme (FP7/2007-2013), under Grant Agreement No. 604182 within the FORMAMP project. The MAX IV Laboratory is acknowledged for beam time at X-ray Synchrotron Beamline 1911-SAXS. The authors thank Romain Mallet and Florence Manero (Service commun d'imageries et d'analyses microscopiques SCIAM, University of Angers, France) for assistance during SEM-imaging, Linnéa Nilebäck (Royal Institute of Technology KTH, Stockholm, Sweden) for assistance during plate reader measurements and Lise-Britt Wahlberg (Uppsala University, Uppsala, Sweden) for performing the CD measurements. 


\section{References}

Akhlaghi, S.P., Ribeiro, I.R., Boyd, B.J., Loh, W., 2016. Impact of preparation method and variables on the internal structure, morphology, and presence of liposomes in phytantriol-Pluronic ${ }^{\circledR}$ F127 cubosomes. Colloids and Surfaces B: Biointerfaces 145, 845-853.

Andersson, D.I., Hughes, D., Kubicek-Sutherland, J.Z., 2016. Mechanisms and consequences of bacterial resistance to antimicrobial peptides. Drug Resistance Updates 26, 43-57.

Barauskas, J., Johnsson, M., Joabsson, F., Tiberg, F., 2005. Cubic Phase Nanoparticles (Cubosomet): Principles for Controlling Size, Structure, and Stability. Langmuir 21, 2569-2577.

Boge, L., Bysell, H., Ringstad, L., Wennman, D., Umerska, A., Cassisa, V., Eriksson, J., Joly-Guillou, M.L., Edwards, K., Andersson, M., 2016. Lipid-Based Liquid Crystals As Carriers for Antimicrobial Peptides: Phase Behavior and Antimicrobial Effect. Langmuir 32, 4217-4228.

Braun, K., Pochert, A., Lindén, M., Davoudi, M., Schmidtchen, A., Nordström, R., Malmsten, M., 2016. Membrane interactions of mesoporous silica nanoparticles as carriers of antimicrobial peptides. Journal of Colloid and Interface Science 475, 161-170.

Böhlen, P., Stein, S., Dairman, W., Udenfriend, S., 1973. Fluorometric assay of proteins in the nanogram range. Archives of Biochemistry and Biophysics 155, 213-220.

Cervin, C., Vandoolaeghe, P., Nistor, C., Tiberg, F., Johnsson, M., 2009. A combined in vitro and in vivo study on the interactions between somatostatin and lipid-based liquid crystalline drug carriers and bilayers. European Journal of Pharmaceutical Sciences 36, 377-385.

Dürr, U.H.N., Sudheendra, U.S., Ramamoorthy, A., 2006. LL-37, the only human member of the cathelicidin family of antimicrobial peptides. BBA - Biomembranes 1758, 1408-1425.

Eckert, R., 2011. Road to clinical efficacy: challenges and novel strategies for antimicrobial peptide development. Future Microbiology 6, 635-651.

Fischer, R.L., Schnorr, K.M., Kristensen, H.-H., Yaver, D., Sönksen, C.P., Elvig-Jørgensen, S.G., Christensen, B., Christensen, B.E., Lehrer, R.I., Frimodt-Moller, N., Ludvigsen, S., De Maria, L., Raventós, D., Mygind, P.H., Kjærulff, S., Buskov, S., Hansen, M.T., Sørensen, M.V., Zasloff, M., Taboureau, O., 2005. Plectasin is a peptide antibiotic with therapeutic potential from a saprophytic fungus. Nature 437, 975-980.

Gontsarik, M., Buhmann, M.T., Yaghmur, A., Ren, Q., Maniura-Weber, K., Salentinig, S., 2016. Antimicrobial Peptide-Driven Colloidal Transformations in Liquid-Crystalline Nanocarriers. The Journal of Physical Chemistry Letters 7, 3482-3486.

Gustafsson, J., Ljusberg-Wahren, H., Almgren, M., Larsson, K., 1996. Cubic Lipid-Water Phase Dispersed into Submicron Particles. Langmuir 12, 4611-4613.

Gustafsson, J., Ljusberg-Wahren, H., Almgren, M., Larsson, K., 1997. Submicron Particles of Reversed Lipid Phases in Water Stabilized by a Nonionic Amphiphilic Polymer. Langmuir 13, 6964-6971. Hancock, R.E.W., Lehrer, R., 1998. Cationic peptides: a new source of antibiotics. Trends in Biotechnology 16, 82-88.

Hancock, R.E.W., Sahl, H.-G., 2006. Antimicrobial and host-defense peptides as new anti-infective therapeutic strategies. Nature biotechnology 24, 1551-1557.

Hartmann, M., Berditsch, M., Hawecker, J., Ardakani, M.F., Gerthsen, D., Ulrich, A.S., 2010. Damage of the Bacterial Cell Envelope by Antimicrobial Peptides Gramicidin S and PGLa as Revealed by Transmission and Scanning Electron Microscopy. Antimicrobial Agents and Chemotherapy 54, 31323142.

Hyde, S.T., 2001. Identification of Lyotropic Liquid crystalline Mesophases, in: Holmberg, K. (Ed.), Handbook of Applied Surface and Colloid Chemistry. John Wiley \& Sons, Ltd, pp. 299-332. Johansson, J., Gudmundsson, G.H., Rottenberg, M.E., Berndt, K.D., Agerberth, B., 1998. Conformation-dependent antibacterial activity of the naturally occurring human peptide LL-37. The Journal of biological chemistry $273,3718-3724$. 
Kasetty, G., Kalle, M., Mörgelin, M., Brune, J.C., Schmidtchen, A., 2015. Anti-endotoxic and antibacterial effects of a dermal substitute coated with host defense peptides. Biomaterials $53,415-$ 425.

Labrador, A., Cerenius, Y., Svensson, C., Theodor, K., Plivelic, T., 2013. The yellow mini-hutch for SAXS experiments at MAX IV Laboratory. Journal of Physics: Conference Series 425, 072019.

Larsson, K., 1989. Cubic lipid-water phases: structures and biomembrane aspects. The Journal of Physical Chemistry 93, 7304-7314.

Lundquist, A., Wessman, P., Rennie, A.R., Edwards, K., 2008. Melittin-Lipid interaction: A comparative study using liposomes, micelles and bilayerdisks. Biochimica et Biophysica Acta (BBA) Biomembranes 1778, 2210-2216.

Mahlapuu, M., Håkansson, J., Ringstad, L., Björn, C., 2016. Antimicrobial Peptides: An Emerging Category of Therapeutic Agents. Frontiers in Cellular and Infection Microbiology 6.

Matougui, N., Boge, L., Groo, A.-C., Umerska, A., Ringstad, L., Bysell, H., Saulnier, P., 2016. Lipid-based nanoformulations for peptide delivery. International Journal of Pharmaceutics 502, 80-97. Meikle, T.G., Zabara, A., Waddington, L.J., Separovic, F., Drummond, C.J., Conn, C.E., 2017. Incorporation of antimicrobial peptides in nanostructured lipid membrane mimetic bilayer cubosomes. Colloids and Surfaces B: Biointerfaces 152, 143-151.

Nordström, R., Malmsten, M., 2017. Delivery systems for antimicrobial peptides. Advances in Colloid and Interface Science 242, 17-34.

Pasupuleti, M., Schmidtchen, A., Malmsten, M., 2012. Antimicrobial peptides: key components of the innate immune system. Critical reviews in biotechnology 32, 143-171.

Pasupuleti, M., Walse, B., Svensson, B., Malmsten, M., Schmidtchen, A., 2008. Rational Design of Antimicrobial C3a Analogues with Enhanced Effects against Staphylococci Using an Integrated Structure and Function-Based Approach. Biochemistry 47, 9057-9070.

Schmidtchen, A., Pasupuleti, M., Mörgelin, M., Davoudi, M., Alenfall, J., Chalupka, A., Malmsten, M., 2009. Boosting Antimicrobial Peptides by Hydrophobic Oligopeptide End Tags. Journal of Biological Chemistry 284, 17584-17594.

Schneider, T., Kruse, T., Wimmer, R., Wiedemann, I., Sass, V., Pag, U., Jansen, A., Nielsen, A.K., Mygind, P.H., Raventós, D.S., Neve, S., Ravn, B., Alexandre, M.J.J.B., Maria, L.D., Andersen, A.S., Gammelgaard, L., Sahl, H.-G., Kristensen, H.-H., 2010. Plectasin, a Fungal Defensin, Targets the Bacterial Cell Wall Precursor Lipid II. Science 328, 1168-1172.

Sjögren, H., Ulvenlund, S., 2005. Comparison of the helix-coil transition of a titrating polypeptide in aqueous solutions and at the air-water interface. Biophysical Chemistry 116, 11-21.

Spicer, P.T., Hayden, K.L., Lynch, M.L., Ofori-Boateng, A., Burns, J.L., 2001. Novel Process for Producing Cubic Liquid Crystalline Nanoparticles (Cubosomes). Langmuir 17, 5748-5756.

Strömstedt, A.A., Pasupuleti, M., Schmidtchen, A., Malmsten, M., 2009. Evaluation of Strategies for Improving Proteolytic Resistance of Antimicrobial Peptides by Using Variants of EFK17, an Internal Segment of LL-37. Antimicrobial Agents and Chemotherapy 53, 593-602.

Umerska, A., Cassisa, V., Matougui, N., Joly-Guillou, M.-L., Eveillard, M., Saulnier, P., 2016a.

Antibacterial action of lipid nanocapsules containing fatty acids or monoglycerides as co-surfactants. European Journal of Pharmaceutics and Biopharmaceutics 108, 100-110.

Umerska, A., Matougui, N., Groo, A.-C., Saulnier, P., 2016b. Understanding the adsorption of salmon calcitonin, antimicrobial peptide AP114 and polymyxin B onto lipid nanocapsules. International Journal of Pharmaceutics 506, 191-200.

Valcourt, C., Saulnier, P., Umerska, A., Zanelli, M.P., Montagu, A., Rossines, E., Joly-Guillou, M.L., 2016. Synergistic interactions between doxycycline and terpenic components of essential oils encapsulated within lipid nanocapsules against gram negative bacteria. International journal of pharmaceutics 498, 23-31.

Vandoolaeghe, P., Tiberg, F., Nylander, T., 2006. Interfacial Behavior of Cubic Liquid Crystalline Nanoparticles at Hydrophilic and Hydrophobic Surfaces. Langmuir 22, 9169-9174. 
Wessman, P., Morin, M., Reijmar, K., Edwards, K., 2010. Effect of $\alpha$-helical peptides on liposome structure: A comparative study of melittin and alamethicin. Journal of Colloid and Interface Science 346, 127-135.

Zetterberg, M.M., Reijmar, K., Pränting, M., Engström, Å., Andersson, D.I., Edwards, K., 2011. PEGstabilized lipid disks as carriers for amphiphilic antimicrobial peptides. Journal of Controlled Release 156, 323-328. 